to support rural populations in suing polluting industrialists. To ensure sustainability of the country's huge production system, industrialists must embrace the green economy and tackle factory pollution at source. Hong Yang University of Southampton, UK. hongyanghy@gmail.com Roger J. Flower, Julian R. Thompson University College London, UK.

\section{Metrics: a long-term threat to society}

A predictive $h$-index formula for measuring a scientist's potential success (D. E. Acuna et al. Nature 489, 201-202; 2012) might be convenient for decisionmaking by hiring committees and funding agencies, but such metrics threaten the researcher's wider contribution to society.

Long-term creativity is needed if scientists are to inspire the younger generation. As Albert Einstein said, "creativity is the residue of time wasted" — but researchers are no longer in a position to waste time.

Research pressures also curtail the quality of teaching and supervision, and disadvantage mothers who are trying to build a scientific career (K. R. O’Brien and K. P. Hapgood Oikos 121, 999-1004; 2012). Moreover, early burnout means that some highly trained scientists are being lost to society.

Malgorzata Blicharska, Grzegorz Mikusinski Swedish University of Agricultural Sciences, Uppsala and Riddarhyttan, Sweden. malgorzata.blicharska@slu.se

\section{Metrics: a fetish for high-profile journals}

Precise research indicators may be crucial to the field and useful for grant committees, but the failings of the predicted $h$-index proposed by Daniel Acuna et al. mean that it is unlikely to be classed among them (Nature 489, 201-202; 2012).

For example, the $h$-index ranking of two co-authors of a research paper can be reversed if they have different individual $h$-indices to start with (L. Waltman and N. J. Van Eck J. Am. Soc. Inform. Sci. Technol. 63, 406-415; 2012). Also, the formula for predicting an $h$-index is probably valid only for neuroscientists, given that different fields have other significant features. The formula's structure does not consider publications in conference proceedings or in books as variables, thereby exacerbating the fetishism surrounding publication in high-profile journals.

Ronald Rousseau University of Antwerp, Belgium.

ronald.rousseau@ua.ac.be Xiaojun Hu Zhejiang University School of Medicine, Hangzhou, China.

\section{Metrics: allow more gradual progress}

New metrics designed to evaluate a scientist's potential, such as a future $h$-index depending on past trajectories (D. E. Acuna et al. Nature 489, 201-202; 2012), fuel the delusion that only fast results count. Progressive paradigms based on mature ideas, meticulous work, sound ethics, patience and cooperation may be slower, but they still contribute to science in the long term (J.-F. Lutz Nature Chem. 4, 588-589; 2012).

French physicist Louis de Broglie (1892-1987), a pioneer of quantum mechanics, once declared that had Isaac Newton lived in his day and age, Newton might never have become a scientist at all. He would have been bewildered by today's academic rat race and would probably have confined himself to his post as Warden of the Royal Mint instead.

Pedro Cintas University of Extremadura, Badajoz, Spain. pecintas@unex.es

\section{Librarians or science informationists?}

As representatives of an international group of library directors, scientists and research administrators, we recognize that science librarians have evolved into 'science informationists' (see go.nature.com/jmvjej). This more accurately reflects their expanded responsibilities, interdisciplinary skills and specialized knowledge.

The increasing volume and complexity of knowledge demands new organizational techniques. Transforming library services calls on technological advances in searching, visualization, data mining and analysis. As technologies and data sources proliferate, there is a growing need to educate students and researchers about these capabilities.

Science informationists collaborate with scientists to enhance their research by helping them to assess its impact, and to curate and manage data. They make knowledge accessible, for example by using their skills in tailoring vocabularies and ontologies. They preserve and showcase their institutions' intellectual output by building networked repositories, and they work with publishers to improve standards, platforms, publication models and search facilities in the interests of better communication.

Science informationists also build sustainable systems through broad collaborations and seek out the best ways to develop these relationships within their institutions. Like researchers, they understand that science needs risk-takers, innovators and visionaries.

Ludmila Pollock ${ }^{\star}$ Cold Spring Harbor Laboratory, Cold Spring Harbor, New York, USA. pollock@cshl.edu ${ }^{*}$ On behalf of 5 co-authors (for a full list, see go.nature.com/88nzz6).

\section{Clean stoves benefit climate and health}

Some 3 billion people worldwide are dependent on rudimentary stoves that burn wood, dung or coal. These account for about $20 \%$ of black-carbon emissions globally, as well as 2 million deaths annually from smoke inhalation. More-sophisticated stoves could dramatically reduce these figures, helping to combat climate change and improve public health.
Conventional stoves that burn solid fuels release black and brown carbon particles, along with gases that are implicated in climate warming (including carbon dioxide, ozone-producing gases and methane). As superefficient absorbers of sunlight, these particles also affect agricultural crop yields.

Modern stoves with natural convection halve solid-fuel use, saving money and collection time. Forced-convection stoves equipped with a fan to increase combustion efficiency cut particulate emissions by $80-90 \%$, black carbon by $60-90 \%$ and ozone-producing gases by 50-90\% (J. Jetter et al. Environ. Sci. Technol. 46, 10827-10834; 2012; and A. Kar et al. Environ. Sci. Technol. 46, 2993-3000; 2012). Clean fuels, such as liquid petroleum gas, biogas or ethanol, would cut these emissions further

The Global Alliance for Clean Cookstoves (www. cleancookstoves.org), which has almost 400 partners, including 36 countries, aims to have 100 million homes adopt clean and efficient stoves by 2020. It is developing financing tools for businesses and consumers to ensure that these user-friendly cooking stoves are affordable and available to all.

The Climate and Clean Air Coalition to Reduce Shortlived Climate Pollutants (www. unep.org/ccac) offers a new opportunity to promote energyefficient stoves that specifically lower black-carbon emissions. Susan Anenberg ${ }^{\star}$ Department of State and Environmental Protection Agency, Washington DC, USA.

anenberg.susan@epamail.epa.gov ${ }^{\star}$ On behalf of 4 co-authors (for a full list, see go.nature.com/pmlupe).

CONTRIBUTIONS

Correspondence may be submitted to correspondence@nature. com after consulting the author guidelines at http:// go.nature.com/cmchno Alternatively, readers may comment online: $w w w$. nature.com/nature. 